chromatograph was dipped in 2 per cent aniline trichloroacetate (in glacial acetic acid). This was air-dried and then oven-heated $\left(110^{\circ} \mathrm{C}\right.$. for $5 \mathrm{~min}$.). A similar determination of sugars was also made by the descending paper chromatographic technique using pyridine, butanol, glacial acetic acid and water $(6: 4: \mathrm{I}: 3)$ as solvent. The concurrent results by aforementioned two techniques are given in Table $\mathbf{1}$.

Table 1. Free Monosaccharides present in Four Typical Solls Monosaccharides Pocomoke soil Sable soil Cecil soil Brazil soil Galactose Glucose Mannose Arabinose Xylose

Rhameose

Sable soil and Brazil soil have two more same unidentified monosaccharides.

The present results indicate that common sugars exist in free condition in soil organic matter. It is very significant to note that glucose was observed in all the four samples. Further work is in progress on the determination of these sugars in widely different soil samples and to investigate the importance of this observation.

I thank Prof. G. T. Felbeck, jun., for advice.

This communication is published with the approval of the Director of the Delaware Agricultural Experiment Station; funds for the investigation were provided by Andelot, Ine., through the University of Delaware Research Foundation.

Department of Agronomy and

Agricultural Engineering,

University of Delaware,

Newark, Delaware.

${ }^{1}$ Forsyth, W. C. G., Biochem. J., 46, 141 (1950).

${ }^{2}$ Lynch, D. L., Wright, L. M., and Olney, H. O., Soil Sci., 84, No. 5, 405 (1957).

${ }^{3}$ Parsons, J. W., and Tinsley, J., Soil Sci., 92, No. 1, 46 (1961)

4 Johnston, H. H., Soil Sci., Soc. Amer. Proc., 25, No. 5, 415 (1961).

${ }^{5}$ Brown, R., Robinson, E., and Johnson, A. W., Proc. Roy. Soc., B 136, 577 (1950).

\section{Alteration in the Surface Properties of Soils by Ion Exchange Resins}

WHEN soils suspended in glass-distilled water were labelled with phosphorus-32, the rapidly exchanging fraction of the isotopically labile phosphate reacted during the first $10 \mathrm{hr}$. according to a first-order mechanism, either by 'film' diffusion or by 'mass action'. Suspensions of the soils with mixed resins ( $\mathrm{Na}^{+}$: 'Zeokarb 225', and Cl- : 'Amberlite IRA 401') behaved quite differently. The rate at which this fraction of the soil phosphate was exchanged by chloride ions from the strongly dissociating resin exchanger was governed by 'bulk' or 'intra-particle' diffusion during 4 days. The mixed resins removed little or none of the remaining 'slowly' exchangeable part of the isotopically labile soil phosphate. (In the absence of resins, this 'slow' fraction exchanged isotopically according to a single 'bulk' diffusion mechanism.) Phosphate diffusion within the resin particle was not the factor controlling the rate of exchange in mixed suspensions of soil and resin because exchange equilibrium was reached in less than 15 min. with Cl : 'Amberlite IRA 40I' alone in phosphate solutions.

A typical soil in water exchanged $4.8 \mathrm{mgm}$. of phosphorus per $100 \mathrm{gm}$. soil isotopically during $10 \mathrm{hr}$. by first order kinetics. When reacted with the 'mixed' resin system the soil exchanged a maximum of $7 \cdot 3$ mgm. phosphorus for $\mathrm{Cl}^{-}$ions, of the same specific activity as the 'rapid' isotopically labile phosphate, in 4 days by 'bulk' diffusion kinetics. The apparent diffusion coefficient, $D_{i}$, for the movement of phosphate ions through soil particles of weighted mean diameter $2 \cdot 9 \mu$ in the clay + silt fraction was $3 \cdot 0 \pm$ $0.5 \times 10^{-10} \mathrm{~cm} .^{2} \mathrm{hr} .^{-1}$.

This evidence suggests that poly-electrolyte anions, products of the chemical and abrasive decomposition of resins, are formed when resin and soil are suspended in water. Phosphate ions held on the soil surface initially must diffuse to the soil solution through multi-layers of such surface-active poly-electrolyte anions on the soil. This leads to the large differences observed in both the mechanisms and the specific rate of exchange of phosphate ions in soil suspended in water with and without resins.

Anomalous surface effects on glass in conductivity water, prepared by using 'mixed bed' ion-exchange resins, have been attributed to weakly basic poly. electrolytes released from the resins ${ }^{1}$. These con taminants appear to be removed by passing through 'Millipore' filters', but their size prevents them from penetrating resin particles of opposite charge ${ }^{3}$. Similarly, non-chelating anions like monovalent phenyl-barbiturate 'block' soil pores and decrease the rate of isotopic exchange of the soil phosphate.

Increasing use is being made of resins to extract nutrients from the soil and to supply nutrients to plants in studying plant nutrition. Our work indicates that caution is needed in interpreting results from such experiments especially when considering rates of reaction and rates of uptake by plants.

In the example given here the 'slow' fraction of the isotopically labile phosphate, $12.8 \mathrm{mgm}$. phosphorus per $100 \mathrm{gm}$. soil, exchanged isotopically during 10-288 hr. with an internal self-diffusion coefficient, $D_{i}^{s}$, equal to $0.8 \pm 0.1 \times 10^{-10} \mathrm{~cm}^{2} \mathrm{hr} .{ }^{-1}$. This is a quarter of the diffusion coefficient obtained by 'mass flow' in the resin : soil system for the phosphate exchanging for $\mathrm{Cl}$ - ions, suggesting that little of this 'slow' fraction would be extracted by the 'mixed' resins.

\section{V. VAIDYANATHAN}

O. TALIBUDEEN

Rothamsted Experimental Station, Harpenden, Herts.

1 Klein, D. H., and Gordon, L., Talanta, 2, 283 (1959).

${ }^{2}$ Boyd, G. E., Adamson, A. W., and Myers, I. S., J. Amer. Chem. Soc. 69, 2836 (1947).

${ }^{3}$ Schenkel, J. H., and Kitchener, J. A., Nature, 182, 131 (1958).

4 Arambarri, P., and Talibudeen, O., Plant and Soil, 9, 343 (1959).

\section{PSYCHIATRY}

\section{Isolation and Characterization of a Compound from the Urine of Schizophrenics}

THE systematic screening of schizophrenic and normal urine in this laboratory has led to the identification of a biologically active compound in urine of schizophrenies. This compound is of particular interest since it does not have the usual sympathomimetic actions of the closely related catecholamines, but does have a depressant effect on the central nervous system ${ }^{1}$.

Samples of urine were collected from a series of 19 schizophrenie patients and 14 normal subjects. Neither patients nor controls had been treated 